\title{
DOCUMENTOS
}

\section{Festival Pedro Humberto Allende, 4 al 12 de septiembre de 2017}

\author{
editados por \\ Daniela Fugellie Videla \\ Instituto de Música, Universidad Alberto Hurtado, Chile \\ dfugellie@uahurtado.cl
}

Entre el 4 y el 12 de septiembre de 2017 se realizó en Santiago de Chile el Festival Pedro Humberto Allende, organizado por la Fundación Pedro Humberto Allende en colaboración con el Consejo Nacional de la Cultura y las Artes, la Facultad de Artes de la Universidad de Chile, la Academia Chilena de Bellas Artes del Instituto de Chile, el Goethe Institut Santiago y el Ministerio de la Cultura y las Ciencias de Nordrhein-Westfalen, Alemania. En el marco del festival fue invitado el compositor chileno Juan Allende-Blin (*1928), residente desde fines de la década de 1950 en Alemania, desde donde viajó para compartir experiencias en torno a su propia trayectoria musical y la de su tío, Pedro Humberto Allende (1885-1959).

El Festival contó con actividades diversas, orientadas tanto a profesionales del ámbito musical como a jóvenes y público en general. El evento inaugural del 4 de septiembre consistió en una conferencia magistral a cargo de Juan Allende-Blin concerniente a su obra. Al día siguiente el pianista alemán Thomas Günther ofreció un concierto con obras tanto de Allende-Blin como de compositores futuristas rusos.

El miércoles 6 de septiembre la Asociación Nacional de Compositores realizó un Encuentro Nacional, que constó de una conversación abierta con Juan Allende-Blin acerca de su método de enseñanza de la composición y una mesa de conversación, moderada y coordinada por Gabriel Matthey, acerca de la enseñanza de la composición en Chile, en la que participaron Alejandro Guarello, Aliocha Solovera, Pablo Aranda y Eduardo Cáceres.

El viernes 8 y sábado 9 de septiembre la Orquesta Sinfónica Nacional de Chile, bajo la dirección de Juan Pablo Izquierdo, ofreció un concierto con obras de Pedro Humberto Allende (Concierto Sinfónico para violonchelo y orquesta, 1915) y Juan Allende-Blin (Transformations I para piano, vientos y percusión, 1951), además de la interpretación concertante de un fragmento de la ópera La Chute de la Maison Usher, de Claude Debussy, reconstruido por Allende-Blin. Durante este concierto sinfónico, el compositor fue distinguido por el Rector Ennio Vivaldi con la Medalla Rectoral de la Universidad de Chile, además de recibir de las manos del Ministro de Cultura, Ernesto Ottone, la Orden al Mérito Pablo Neruda. Los conciertos sinfónicos tuvieron un carácter formativo, por lo que se distribuyeron entradas entre jóvenes músicos de la Fundación de Orquestas Juveniles e Infantiles (FOJI), del Liceo Experimental Artístico, el Instituto Profesional Escuela Moderna de Música y Danza y la Universidad de Chile.

Por último, el martes 12 de septiembre Juan Allende-Blin fue incorporado a la Academia Chilena de Bellas Artes en calidad de Miembro Honorario. Junto con el discurso de recepción a cargo del presidente de la institución, Luis Merino Montero, el acto contó con un discurso de Allende-Blin, además de un concierto de obras para piano y lieder tanto de su autoría como de Pedro Humberto Allende. Si bien estas diversas actividades fueron posibles gracias a los esfuerzos de diferentes instituciones, es posible destacar la valiosa labor de Luis Merino en la coordinación general del proyecto.

En general, el festival ofreció un acercamiento a la obra de Pedro Humberto Allende y de Juan Allende-Blin desde diversos ángulos musicales y reflexivos, los que incluyeron también la discusión 
en torno al legado del primer compositor mencionado y de otros creadores musicales chilenos que, como él, se han abocado a la enseñanza de la composición. En este sentido, se puede afirmar que las charlas y conversaciones realizadas durante este festival ofrecieron puntos de vista profundos en torno a la música chilena, cuyo valor se ve reforzado por constituir un punto de encuentro que, en su magnitud, no se realiza frecuentemente en el país.

La decisión de editar estas charlas surge así del convencimiento de que constituirán documentos valiosos para el estudio de la música chilena docta del siglo XX. La conferencia magistral de Juan AllendeBlin (I) ofrece un panorama general de su creación musical y los principios estéticos e ideológicos que la sustentan. Debido a que el compositor ha desarrollado la mayor parte de su carrera en Alemania, hasta ahora la bibliografía más importante acerca de su obra se ha publicado en alemán ${ }^{1}$, por lo que esta conferencia ofrece a los lectores hispanohablantes la posibilidad de adentrarse en su trayectoria.

Este documento se complementa con el discurso de recepción de Juan Allende-Blin como Miembro Honorario de la Academia Chilena de Bellas Artes por parte de Luis Merino Montero (II), el que abarca la carrera artística y académica del compositor desde diversas perspectivas, además de ofrecer informaciones del Festival y sus objetivos.

El discurso de incorporación a la Academia Chilena de Bellas Artes de Juan Allende-Blin (III) profundiza específicamente en su interés por la cábala y las relaciones entre música y lenguaje. Es factible agradecer al compositor por su colaboración en la edición de sus charlas, sus cuidadosas revisiones y el envío de un apéndice escrito expresamente para esta publicación.

Por último, la mesa de conversación "La enseñanza de la composición en Chile" (IV) ofrece las visiones de cuatro compositores actualmente abocados a la enseñanza en Santiago de Chile, constituyendo un interesante documento que complementa trabajos anteriormente publicados por la Revista Musical Chilena respecto de la enseñanza de la creación musical en el país ${ }^{2}$. La edición de este último documento, que fue transcrito, editado y posteriormente revisado por los compositores participantes, fue posible gracias al trabajo en conjunto con Gabriel Matthey, quien estuvo a cargo de la edición final. Quedan pendientes para una futura publicación las reflexiones de Juan Allende-Blin acerca de la enseñanza de la composición, las que por razones de fuerza mayor no pudieron ser incluidas en esta serie de documentos.

\section{JUAN ALLENDE-BLIN, CONFERENCIA MAGISTRAL \\ Lunes 4 de septiembre de 2017, Biblioteca Nacional de Chile, Sala Ercilla}

Es para mí muy emocionante poder relatar en un tiempo relativamente breve toda mi evolución que partió desde aquí en Santiago durante los años 30 y 40 del siglo XX. Siendo yo niño hubo un acontecimiento muy especial que me quedó grabado para siempre: fue la visita del pianista Ricardo Viñes en casa de mis padres. Sus bigotes, cuya simetría señalaba decididamente hacia arriba me produjeron una hilaridad reprimida. Pero cuando Viñes se sentaba frente al teclado y tocaba alguna obra de Claude Debussy o alguna Tonada de Pedro Humberto Allende mi hilaridad contenida se transformaba instantáneamente en una admiración seria y nostálgica, porque me transportaba a no sé dónde. Al mundo de los sonidos.

1 Luis Merino menciona algunas publicaciones alemanas en su discurso de incorporación (III). Véase Stefan Fricke y Werner Klüppelholz (ed.), Ein Leben aus Erinnerung und Utopie, Saarbrücken 2002; y Juan Allende-Blin (ed.), Musiktradition im Exil. Zurück aus dem Vergessen, Colonia 1993. La Revista Musical Chilena igualmente ha publicado trabajos de Juan Allende-Blin: "Algunos aspectos de la música actual: panorama y retrospectiva" (RMCh, XXIV/110, 1970, pp. 33-38); "En busca del Debussy perdido" (RMCh, XLIX/184 1995, pp. 11-37) y "Pedro Humberto Allende Saron. Algunos aspectos característicos de su obra" (RMCh, LVI/197, 2002, pp. 77-80).

2 Junto con el conocido trabajo de Gustavo Becerra, "Crisis de la enseñanza de la composición en Occidente”, aparecido en la Revista Musical Chilena entre 1958 y 1959, véase por ejemplo Luis Merino, "Bienvenida a Gustavo Becerra" (RMCh, XLII/170, 1988, pp. 87-89). La Revista Musical Chilena LI/187 (1997), pp. 42-62, ofrece diversas perspectivas de Fré Focke como profesor de composición, mientras RMCh LIX/203 (2005), dedicada a Cirilo Vila, también abarca aspectos de su labor como profesor de esta disciplina. 
Junto con esa imagen de mis primeros recuerdos se encuentra, en ese inmenso claustro que es nuestra memoria, la silueta perfilada de mi tío Humberto con su cabellera alba. La familia de mi tío vivía en aquellos años en un impasse, o sea, en una pequeña calle sin salida -como las hay en ciertos barrios de París. Son calles íntimas, cordiales, porque los pocos vecinos se conocen.

Otro recuerdo musical de aquellos años es del ciudadano Soto, un músico anarquista que visitaba la casa de mis padres. Siempre vestido con un overol azul y una boina vasca. Yo ya había comenzado a componer con la ayuda de mi madre, que me enseñó las notas por medio de un juego de figuras metálicas. Llaves, pentagramas, notas blancas, negras, silencios, todas estas figuras eran elementos metálicos que yo podía mover libremente. Así aprendí la escritura musical y poco a poco comencé a componer, moviendo estos elementos sorprendentes. De allí que no me fue difícil imitar en un papel pentagramado todo aquello que yo había manipulado con mis elementos metálicos. Sin esforzarme escribía posteriormente notas en el papel. Mi madre me daba lecciones de piano. Lo escrito lo hacía sonar. Era una maravilla inventar sonidos con el teclado y después -siempre con la ayuda de mi madre- poder anotarlos en el papel pentagramado. Así aprendí a inventar melodías que formaban frases como con el lenguaje hablado.

Pero yo quería referirme al ciudadano Soto, anarquista conectado con los anarquistas españoles. Años después de mis primeros juegos musicales, apareció el ciudadano Soto y me pidió una marcha para ejecutarla con su banda de ciudadanos anarquistas. Orgulloso de obtener tal encargo, le compuse una marcha. No recuerdo si jamás se ejecutó aquella composición sin duda bien primitiva, pero esta historia me quedó en mi memoria, porque en esos años comenzó la horrenda Guerra Civil española, una guerra que mi familia observaba con apasionado interés.

A los quince años inicié mis estudios de composición con mi tío Humberto. Para mi cumpleaños me regaló mi tío la partitura del Pierrot lunaire de Arnold Schönberg -un regalo valioso que me invitó a descubrir un nuevo mundo sonoro-. Las primeras clases de mi tío me introdujeron en la armonía a cuatro voces. El libro de Bussler ${ }^{3}$ servía de guía. Después de haber avanzado en esta técnica, empezó a darme clases de composición.

El margen formal lo proporcionaba Stephen Heller o Robert Schumann. Analizando los Estudios de Heller o las Piezas Infantiles de Schumann se destilaba la forma -en general simple- de esas obras. La composición balbuceante trataba de alejarse del idioma propuesto, guardando eso sí el margen formal. Interesantes resultaban los análisis de obras de Tomás Luis de Victoria, de Palestrina, pero también de Bach, de Beethoven, Mendelssohn o Schumann.

Las clases se desarrollaban en la casa del tío. Como Intermezzo él me invitaba a tocar piano a cuatro manos. Entonces ejecutábamos por ejemplo Ma mère l'oye de Ravel, o las Danzas sinfónicas de Grieg. De vez en cuando sacaba el tío Humberto de su estante extraordinariamente bien ordenado sus Piezas para piano a cuatro manos. Esto era una deferencia especial.

Pedro Humberto Allende había analizado minuciosamente en sus años de juventud una enorme cantidad de música: El clavecín bien temperado, los Estudios de Chopin, las sonatas para piano y los cuartetos de Beethoven. Un interés muy especial le dedicó mi tío a estudiar la obra de César Franck. En el discurso musical de Franck descubrió su técnica de composición, que Franck denominó forme cyclique. Esta forma cíclica era en el fondo un retorno transformado de la técnica de las misas polifónicas del Renacimiento: Ockeghem, Josquin des Près como casi todos sus colegas de los siglos XV y XVI utilizaban una melodía litúrgica, un cantus firmus que modelaban en fragmentos que van apareciendo en las cinco partes componentes de la misa polifónica, dando así una unidad a esas obras. El tenor tiene, sostiene (esa es la etimología de la palabra), cantando la melodía litúrgica que sirve de base a estas obras de largo aliento. Fragmentos del cantus firmus aparecen en el tenor variando su ritmo y produciendo al repetir los intervalos que hacen del cantus firmus una unidad formal subcutánea.

Franck no elige un cantus firmus sino un motivo característico que en los otros movimientos de la obra aparece transformado. El motivo o célula inicial se traspone, cambia de ritmo, cambia de color instrumental, cambia de carácter en cada nuevo movimiento. Aun cuando las transformaciones de la célula inicial se aparten de ella, su estructura es reconocible y puede de esta manera dar unidad a obras de grandes dimensiones. Pedro Humberto Allende utilizó este procedimiento en forma magistral en su Concierto sinfónico para violoncello y orquesta de 1916. Esta obra se interpretará el próximo viernes 8 y el sábado 9 de septiembre por la Orquesta Sinfónica Nacional de Chile en el concierto que se

3 Ludwig Bussler, Harmonielehre, Praktische Systematisch-methodisch Dargestellt, Berlín: Carl Habel, 1930. 
realizará en el Teatro de la Universidad de Chile, bajo la dirección del maestro Juan Pablo Izquierdo, con Sebastián Escobar como solista en violoncello.

El fundamento de su pensamiento musical provenía de César Franck y durante sus viajes a París conoció a Vincent d'Indy, quien fue el alumno más meticuloso del maestro. D’Indy escribió un Cours de Composition Musical que forma una biblioteca de fascículos que contienen la historia de la evolución de la música y es de una erudición sorprendente. Por ejemplo, al tratar el motete del siglo XIII cita d'Indy versos de la Commedia de Dante, del libro del Purgatorio y del Paraíso, versos que describen en forma poética el motete contemporáneo del poeta que inventó la nueva lengua italiana. Los versos que cita D'Indy describen un paseo de Dante en un bosque y los pájaros cantan en la cima y otros entonan un bourdon con sus rimas.

Los fascículos que componen el Curso de Composición de D'Indy contienen tanto una historia de la música hasta Claude Debussy como, por otra parte, análisis especialmente de las sinfonías de Beethoven. Este Curso de Composición le servía a mi tío como guía relativo para su curso de composición.

Pedro Humberto Allende ampliaba y variaba constantemente su método de enseñanza. Mi tío analizaba las obras de Debussy, de Ravel, de Manuel de Falla -mientras que D'Indy solo las nombraba. Recuerdo un análisis de la orquestación de la ópera de Ravel L’heure espagnole, en donde él hacía uso de sus profundos conocimientos de acústica.

Pedro Humberto Allende tenía una posición política bien definida; él era un hombre de izquierda, de una izquierda abierta, sin dogmas, pensamientos heredados de su padre, Juan Rafael Allende, o sea de mi abuelo. De allí se desprendía también la ley moral de mi tío: ser responsable de cada nota que uno compone. Fue para mí su lección esencial. Las clases que yo recibí fueron casi familiares y solo al final me inscribí oficialmente en el Conservatorio como su alumno de composición.

Tal vez en 1947 o 1948 mi tío fue jubilado y yo pasé a la clase de René Amengual, su exalumno. Amengual, hábil pianista y compositor de talento, había obtenido una beca para estudiar en Estados Unidos. Fue allí alumno de Hindemith en composición y de Artur Schnabel en piano. La influencia de Hindemith, que se manifestaba en un empleo exclusivo de la música diatónica, marcó entonces al compositor René Amengual, que a su vez me recomendaba una simplicidad en la estructura y la exclusión de las armonías cromáticas. Estas ideas me contrariaban, pues la escuela que yo había recibido promulgaba lo contrario. Yo me había inclinado desde un principio a una riqueza tanto melódica como armónica y rítmica. La obra de Pedro Humberto Allende me había indicado el camino que conduce a visiones más densas y complejas.

A veces suceden cosas que corroboran una decisión solitaria. Mi camino en aquellos tiempos no era ni oportuno ni actual, porque las modas neoclásicas estaban bajo la tutela de compositores de renombre, como Paul Hindemith o Igor Stravinsky. En mi decidido y consciente aislamiento fui un día a la librería de la Universidad de Chile y busqué libros que pudiesen interesarme. No sé en qué rincón encontré un libro que me iba a acompañar toda mi vida y que entonces me servía de consuelo en mi aislamiento: Introduction à la musique de douze sons del compositor René Leibowitz. Poco antes había compuesto yo una obra en la que empleaba la forma cíclica heredada de mi tío Humberto, pero ampliándola y rompiendo los moldes de la tonalidad ${ }^{4}$.

El libro de Leibowitz contiene un análisis exhaustivo de las Variaciones para orquesta op. 31 de Arnold Schönberg. En los últimos capítulos de este libro, Leibowitz presenta no solo las obras posteriores a estas Variaciones para orquesta, sino que además analiza obras de compositores jóvenes influenciados por Schönberg, como Ernst Krenek, Paul Dessau, Erich Itor Kahn. Este nuevo mundo me fascinó y me produjo el inmenso deseo de obtener las partituras parcialmente reproducidas en este libro.

Hay libros que invitan a viajar. Así fue el caso del libro de Leibowitz. Desde hacía años que yo deseaba conocer las tierras de mis antepasados, pero también las tierras de los autores de estas partituras o de aquellas novelas o de aquellos cuadros que yo admiraba tanto. En la primera oportunidad partí con rumbo a Francia y a una Alemania en ruinas.

Pero en esos años que se han hundido en mi memoria, solo se podía partir en barco. Y los barcos hacían extensas escalas. Así es que recorrí las calles de Río de Janeiro, de Lisboa, de París. Allí visité a mis parientes y me imbuí en los barrios de ese París melancólico d'après-guerre donde todo el mundo se disputaba entre surrealismo y existencialismo.

4 En este punto se hizo oír una grabación del tercer movimiento de la Sonatina para piano de Juan Allende-Blin, dedicada a Jean Cébron. 
Instalándome en Alemania Occidental visité en 1952 los Cursos Internacionales de Verano de Nueva Música en Darmstadt. Olivier Messiaen había terminado recientemente sus Cuatro Estudios de ritmo que él mismo ejecutó en un impecable frac rodeado de alumnos en tenida de sport. Magníficos ejecutantes presentaron el Pierrot lunaire de Arnold Schönberg, el Cuarteto Vegh nos hacía oír todos los cuartetos de Béla Bartók comentados por Sandor Vegh. La joven generación de Luigi Nono, Pierre Boulez, Karlheinz Stockhausen preparaba la ejecución de sus recientes composiciones. Olivier Messiaen analizaba genialmente Le sacre du printemps de Stravinsky. Yo asistía a estos cursos junto con Gerd Zacher, quien compartió mi vida durante sesenta y dos años.

Antes de dirigirme a Europa yo había compuesto, entre otras obras, mis Tres Rilke-Lieder que se ejecutarán durante este Festival, más precisamente en el concierto de cámara que se realizará el martes 12 de septiembre en el Salón de Honor del Instituto de Chile. Poco después compuse mis Transformations I. Algunos se preguntarán por qué el título de Transformations. En 1949 o 1950, aquí en Santiago, analizando las Variaciones op. 27 para piano de Anton Webern, observé que eran más radicales que las Variaciones de Arnold Schönberg, pues no poseían un tema, sino que los tres movimientos que componen esta obra desarrollan una continua transformación. Webern creaba un nuevo género que yo denominé Transformations.

$\mathrm{Al}$ relatar mis primeras impresiones de Darmstadt lancé el nombre de mi amigo Gerd Zacher. Lo conocí en Detmold, donde yo estudié composición con Günter Bialas y dirección de coros con Kurt Thomas -futuro Thomaskantor, o sea, sucesor de J. S. Bach-. El primer día del curso de composición en Detmold, Günter Bialas me presentó a sus alumnos, entre ellos Gerd Zacher, que ya se destacaba además como un excelente organista. Cada alumno tocaba una composición. Gerd Zacher me llamó la atención con su cantata Prière pour aller au paradis avec les ânes sobre un bello poema de Francis Jammes. Él cantó la parte solista en francés y, leyendo la partitura para ocho instrumentos de viento y piano, ejecutó toda la obra al piano. Esto se efectuaba en los primeros días de enero de 1952, o sea, pocos años después de la derrota de la Alemania nazista, que consideraba a Francia como el enemigo ancestral. Poner en música un poema francés era en esos años un acto audaz; el odio y los prejuicios contra Francia eran entonces muy virulentos.

Mi amigo compositor y organista me invitó a una iglesia donde él practicaba el órgano. Era el instrumento que Johannes Brahms había tocado en su juventud. Allí aprendí a conocer este complejo instrumento y su inmenso repertorio, que yo conocía casi solamente por medio de discos y de partituras. Cada instrumento alberga una historia. La historia del órgano durante la era nazista es especialmente mezquina y reaccionaria. Hasta la época del organista y compositor Max Reger juega el órgano un rol singular y extraordinario por la calidad del repertorio. Desde los comienzos de este instrumento se escriben obras maestras para el órgano, en toda Europa. A pesar que durante el medievo y la época barroca no había medios de comunicación comparables a los de hoy, los compositores de entonces se transmiten sus obras, se copian, se editan. Bach conoce perfectamente por ejemplo las composiciones de Frescobaldi, de Vivaldi, de Nicolas de Grigny, de André Raison y naturalmente las de Sweelinck, de Buxtehude, de Matthias Weckmann. También existía un intenso intercambio entre España y Austria en la época de Carlos V y de Felipe II. Es increíble que al investigar escrupulosamente los intercambios entre músicos desde el medievo hasta el siglo XIX se descubren influencias mutuas entre los más importantes compositores.

En pleno siglo XX, entre 1933 y 1945, Hitler y sus adeptos logran cortar toda comunicación con lo que se pueda considerar como "extraño" o "extranjero". Los nazis designan menospreciablemente estas obras como productos judíos-bolcheviques. Para los nazis los bolcheviques tenían que ser judíos. Las fronteras del III Reich se cierran herméticamente desde 1933. Los compositores que se quedan en el país para colaborar con el régimen, cierran los oídos para evitar cualquier influencia externa que los nazis consideran como "degenerada". Este repliegue ocurre generalmente de modo voluntario, sin presión de las autoridades. Los organistas de la época nazista se reducen a un repertorio exclusivamente alemán y que representa solo la música compuesta entre el siglo XVIII -de preferencia la obra completa de Johann Sebastian Bach- hasta ciertas obras de Max Reger escritas antes de la Primera Guerra Mundial.

Las composiciones de la era nazista tratan de imitar un estilo barroco imaginario. La posición política de estos organistas-compositores se identifica con la de los gobernantes. Una campaña feroz, que se dirige contra los judíos como representantes de la música "degenerada”, acompaña a esta música pseudobarroca compuesta por los fieles adeptos del régimen nazi. Aún más, se trata de destruir no solo un arte independiente y creativo, sino destruir seres humanos. 
Cuando llegué a Alemania en 1951 continuaban en sus puestos todos los funcionarios que habían sido nombrados por los nazis, no solo los funcionarios de la música. O sea, las instituciones musicales seguían en manos de los nazis que oportunamente se ponían una máscara democrática poco convincente. La guerra había terminado con una derrota total, pero las instituciones quedaron en general intactas. Los organistas - por tanto- seguían tocando los mismos programas de la época nazista.

Gerd Zacher y yo fuimos invitados en 1954 por mis padres a venir a Chile. Durante los tres años de nuestra estadía en este país, Gerd Zacher actuó aquí como pianista y como organista. Su repertorio comprendió desde Frescobaldi hasta Purcell, desde Bach hasta Aleksandr Skrjabin. Creó además un conjunto de música antigua, con instrumentos de la época. Al regresar a Alemania como organista en Hamburgo desplegó un amplio repertorio, incluyendo obras de compositores españoles, franceses, italianos, portugueses, norteamericanos y naturalmente también compositores alemanes. Eran compositores desde el medievo hasta los del siglo XX; incluyendo a compositores judíos excluidos de los programas de los organistas alemanes de aquellos años como Felix Mendelssohn Bartholdy o Arnold Schönberg. El repertorio de Gerd Zacher comprendía además algunos de los compositores más importantes de mi generación que fueron invitados a escribir obras especialmente para sus programas.

Yo ya había compuesto una obra para órgano en 1952, la primera de mis obras escrita en Alemania. En Hamburgo compuse varias otras que Gerd Zacher estrenó. Los conciertos de Gerd Zacher, con obras antiguas y contemporáneas, llamaron la atención especialmente entre los músicos de la joven generación y de algunos pocos de las generaciones anteriores. Él componía cuidadosamente sus programas. Pero dentro de la Corporación de la Música Sacra el escándalo fue inmenso. Cartas agresivas con injurias, destrucción sistemática de los afiches de los recitales de Gerd Zacher fueron la reacción de los organistas de aquellos años. Además de difundir falsas noticias infamatorias.

Especial escándalo fueron obras como Improvisation ajoutée de Mauricio Kagel, Volumina de György Ligeti y mi pieza Sons brisés. Para mí, el órgano es un instrumento de viento. Y el viento se puede manejar, se puede flexibilizar. Lo que antes no se realizaba. Al desconectar el motor del órgano, pero tocando por ejemplo un acorde, se va reduciendo la fuerza del viento y entonces se produce lo que yo denomino un arcoíris de sonidos. Los complejos sonoros se desinflan y se descomponen en sus sonidos armónicos. Los diferentes registros producen naturalmente diferentes resultados sonoros. Desconectando y conectando el motor que alimenta el viento se producen estos efectos de colores sonoros que acabo de describir 5 .

Mi lenguaje sonoro se basa en el empleo del total cromático. En cuanto a los elementos rítmicos, trato de evitar el tiempo cronométrico, lo que es casi evidente por medio de los largos sonidos del órgano. Hoy -bajo la iniciativa de Gerd Zacher- se construyen motores que pueden regular el alimento del aire. El órgano tiene la facultad de hacer vibrar el edificio donde está instalado, es la caja de resonancia del instrumento. Es el único instrumento con esta cualidad.

Fuera de varias obras para órgano y música de cámara, había yo compuesto músicas para coreografías de Jean Cébron, quien estuvo muchos años en Chile a partir de 1948. Kurt Jooss había sido invitado para montar sus ballets más célebres: La mesa verde, La gran ciudad, Pavaney Baile en la Antigua Viena. Para ejecutar estos ballets se contrataron a jóvenes danzarines propuestos por Kurt Jooss -el más extraordinario era Jean Cébron-.

Al regresar a Europa, Jean Cébron realizó sus coreografías en la Folkwang-Hochschule para música, danza y artes plásticas, instituto que mantenía un ensamble de ballet. Entre los danzarines que ejecutaban sus ballets se encontraba la joven Pina Bausch. Séquence y Recueil fueron los dos ballets de Jean Cébron con mi música que se ejecutaron en casi toda Europa. La música del ballet Séquence es para flauta, arpa, vibráfono y percusión ${ }^{6}$. El ballet no tiene argumento, sino que es una composición coreográfica articulada en escenas en que un grupo de cinco bailarines alterna con solos. Como Jean Cébron es también un compositor que conoce las técnicas de Messiaen como igualmente las mías, Jean ha transportado en movimientos corporales algunas de ellas. Por ejemplo, la técnica de Olivier Messiaen de los cánones par ajout du point. Estos cánones transportados a brazos y piernas por su aumentación inacostumbrada producen un efecto especial de perspectiva en la escena en que se desarrolla el ballet.

5 Se reprodujo el inicio de Sons brisés, donde el compositor empleó esta técnica.

6 Se reprodujo una grabación de Distances, estracto del ballet, interpretado por Evelin Degen, flauta, Jane Barthe, arpa, Michael Pattmann, vibráfono y Nobert Krämer, Igor Krasovsky y Carsten Langer, percusión. 
Porque cada danzarín realiza los mismos movimientos pero en tiempos diferentes. C'est une perspective inouïe (Es una perspectiva asombrosa).

En 1968 me pidió mi amigo Christoph von Weyhe, un excelente pintor, que se radicó por aquellos años en Paris, una partitura manuscrita con el fin de elegir un fragmento de mi escritura para una revista-afiche que se pegaba en los muros de París en los días revolucionarios de mayo del 68. Él eligió un fragmento de Sons brisés con un comentario mío y dibujos de gran finura de mi amigo Christoph von Weyhe. Por aquellos días había ejecutado Gerd Zacher mis Sons brisés en París, en la iglesia de Saint Séverin, recital al que había asistido Olivier Messiaen. En esos días aparecieron grafitis en los muros de ese París en efervescencia, grafitti que me fascinaron por su poesía que a la vez era política. El grafiti que más me impresionó fue L'IMAGINATION AU POUVOIR (La imaginación al poder).

La radio de Hamburgo me había encargado componer piezas para el magnífico coro de la estación. Yo escribí dos obras en esa ocasión: Erratum musical para tres conjuntos corales repartidos en el espacio -sobre una idea de Marcel Duchamp y Souffle para un pequeño coro con birimbaos y gran coro; una especie de concerto grosso. El coro no canta textos sino solo fonemas; los textos se proyectan en una pantalla grande detrás de los dos coros. Las proyecciones de los textos se van mostrando según lo indica con precisión la partitura. Son tres columnas (o sea tres voces) sobre las cuales se proyectan palabras en varios idiomas y frases o versos, todos ellos se refieren a souffle: aliento, respiración, pneuma, ánima. Los textos culminan al final de la obra con la proyección de la frase L'imagination au pouvoiry con otra de Jean Genet: Endormez le bourreau-. Genet era en aquella época un autor cuyas obras estaban prohibidas. Al separar el texto de la música se produce un contrapunto entre lo visual de los textos proyectados como si fueran voces de la estructura musical, y la música sonora que se desarrolla en otro espacio. Esta y otras obras corales mías se han ejecutado frecuentemente en Hamburgo, Bonn, Colonia y Stuttgart ${ }^{7}$.

Un trompetista muy virtuoso me pidió que le escribiera un trozo para su instrumento. Le respondí que yo no quería componer una pieza virtuosa para trompeta sola, sino que un trío para soprano, trompeta y eufonio. Yo elegí un poema de Hölderlin, de la época final de su vida, cuando la acechante locura lo hacía escribir esbozos fragmentarios. De allí el título de mi obra: Fragment nach Hölderlin. Como en Souffle, la soprano silba y comienza con fonemas extraídos del poema y solo al final canta todo el breve poema. Es una preparación, una aproximación entre el poema y la música. El poema está rodeado de música extraída de los versos, de los fonemas que lo componen. El poema está impregnado por medio de la música y viceversa. El trompetista toca tanto sonidos sobreagudos como sonidos profundos denominados notas-pedales. Además tanto la trompeta como el eufonio producen sonidos multifónicos. El tiempo está articulado en proporciones que no corresponden a la métrica convencional. Desde el sonido más profundo hasta el más agudo aparece cada sonido por lo menos una vez; todos los sonidos cromáticos están así representados dentro de esta obra. El ámbito está completado con un gran número de alturas sonoras y está aún aumentado por algunos sonidos en cuartos de tono. Es un espacio sonoro que se desarrolla dentro de un tiempo que no concuerda con nuestro tiempo cronométrico. Grandes silencios son sonidos inaudibles 8 .

Desde los años 60 comencé a trabajar con grabaciones en cinta magnética con la idea de realizar "collages sonoros", como Picasso o Braque en las artes plásticas donde hay cuadros con trozos de diario junto con formas geométricas pintadas al óleo, un boleto de tranvía o un trozo de madera pueden aparecer igualmente como elementos de la composición del cuadro. Esa fue mi idea matriz para componer "collages-sonores" en donde combino fragmentos de documentos sonoros con sonidos instrumentales o vocales. A veces elijo textos en lenguas diferentes, pero que tienen relaciones entre sí. Uno de ellos es Palimpsest de 1993. Un palimpsesto es un documento en pergamino que en épocas pretéritas se utilizaba más de una vez, cada vez con un nuevo texto. El texto inicial se borraba rasgando sus letras para escribir en el mismo lugar un nuevo texto, pero huellas del texto primero quedaban conservados, pero a penas legible. Con esa idea inicial compuse una obra con tres textos en tres lenguas diferentes. De san Juan de la Cruz escogí mis versos predilectos: las Coplas del alma que pena por ver a Dios con su estribillo genial, muero porque no muero; el segundo texto es del poeta alemán

7 Se reprodujo el comienzo de Souffle, interpretada por el Coro de la radio de Colonia bajo la dirección de Manfred Schreier.

8 Se reprodujo un fragmento de Fragment nach Hölderlin, interpretado por Silvia Weiss, soprano, Sebastian Schär, trompeta, y Andreas Roth, eufonio. 
Alfred Lichtenstein Siegmund Simon y finalmente el Pamphlet contre la Mort de Robert Desnos. Todos estos textos tratan de la muerte. Los dos últimos narran un entierro en forma surreal. Robert Desnos, un resistente de la ocupación nazista de Francia, fue hecho prisionero y llevado a Theresienstadt (Terezín) donde murió de tifus el 8 de junio de 1945.

Para esta obra compuse piezas para piano, órgano y arpa, anotadas tradicionalmente. Tres personas hablan los tres textos: el compositor José Luis de Delás recita las Coplas de san Juan de la Cruz, el poeta y filósofo Jean Pierre Faye lee el poema en prosa de Robert Desnos y el actor Fritz Lichtenhahn el de Alfred Lichtenstein. Yo hice grabar cada pieza de música y cada texto literario separadamente. Gerd Zacher toca el órgano, Sabine Kunkel, el arpa y yo el piano. En el estudio electrónico donde se grabaron estas composiciones autónomas, improvisaron Michael Rießler y Klaus Linder tocando diversos instrumentos de viento, entre ellos el birimbao. Estas improvisaciones se realizaron dentro de moldes precisos que yo les señalé. De estas improvisaciones yo elegí algunos fragmentos. Con este material compuse mi collage sonore. Un trabajo de precisión por una parte y un trabajo aleatorio por otro lado. Aunque trabajé en un estudio electrónico mi obra no es electrónica. Les voy a presentar un fragmento de cerca de 8 minutos de una obra que dura más de 36. Palimpsest, un encargo de la radio de Colonia, lo realicé en el estudio electrónico del Departamento Akustische Kunst-arte acústica. El ingeniero de sonido es Benedikt Bitzenhofer, un mago de las manipulaciones técnicas con un oído extraordinario ${ }^{9}$.

En este género de música he realizado más de una docena de collages sonores. Algunos de ellos tienen un carácter autobiográfico. En 1983 obtuve el premio Karl Sczuka por mi collage sonore Rapport sonore / Relato sonoro / Klangbericht, premio del Südwestfunk Baden-Baden. Los tres idiomas del título explican que el contenido emplea estas tres lenguas.

Es difícil en un tiempo relativamente restringido poder presentar una obra compleja de una larga vida en donde las inquietudes de mi fantasía me han instado a producir músicas de géneros diferentes. Mi inquietud ha sido especialmente de transgredir fronteras de todo orden.

Música y lenguaje / música y el espacio / música y el tiempo / música y la interpretación / música y el azar / música y la sociedad / música y la responsabilidad. Estos son algunos de los temas que han marcado mi vida de compositor. Cuando me refiero a la responsabilidad incluyo allí lógicamente mi posición política que debe provenir de una posición moral: ser responsable no solo de cada nota.

Para terminar esta conferencia quiero presentarles tres canciones yiddisch. Mi amigo Hanns Stein aquí presente, me pidió componer un acompañamiento a una serie de melodías yiddisch que fueron compuestas en los ghettos del Este europeo durante las persecuciones nazistas. Son melodías que se graban profundamente en la memoria porque talentosos músicos y poetas amateurs las crearon bajo la opresión nazista. Eran expresión de la desesperación a la vez que del consuelo con su chispa de humor. Primero compuse un acompañamiento para piano y poco después para un pequeño conjunto instrumental. El estreno de esta versión se efectuó en Hamburgo el 18 de octubre de 1981. El público estaba compuesto de sobrevivientes del campo de concentración de Neuengamme, situado cerca de Hamburgo. Hanns Stein cantó acompañado del conjunto Hinz $\mathcal{E} \mathfrak{乛}$ Kunst dirigido por Alicja Mounk.

\author{
's brent \\ Dort bajm breg fun weldl \\ Sog nischt kejnmal
}

Essen, 11 de agosto del 2017

9 Se reprodujo aquel extracto de Palimpsest. 


\section{LUIS MERINO, DISCURSO DE RECEPCIÓN DE JUAN ALLENDE-BLIN COMO MIEMBRO HONORARIO DE LA ACADEMIA CHILENA DE BELLAS ARTES}

Martes 12 de septiembre de 2017, 19:00 horas, Instituto de Chile, Salón de Honor

En mi calidad de Presidente de la Academia Chilena de Bellas Artes, me corresponde presidir la sesión en la que Juan Allende-Blin se incorporará como Miembro Honorario en los términos de la resolución a que se ha dado lectura al inicio de esta ceremonia. Es admisible señalar que esta sesión no se ajusta al formato en que se acostumbra a realizar este tipo de ceremonias. A ellas se convoca mediante invitaciones formales que extiende la Academia Chilena de Bellas Artes junto con el Instituto de Chile a sus miembros y a personas vinculadas a su quehacer.

En este caso la situación es diferente. Esta ceremonia forma parte de un proyecto mayor: el Festival Pedro Humberto Allende. Ha sido organizado por la Fundación Pedro Humberto Allende, con la colaboración de la Facultad de Artes de la Universidad de Chile, el Centro de Extensión Artística y Cultural de la Universidad de Chile, la Academia Chilena de Bellas Artes del Instituto de Chile y la Asociación Nacional de Compositores, junto con el patrocinio de la Universidad de Chile, la Biblioteca Nacional de Chile, el Ministerio de Cultura y el Fondo de Fomento a la Música Nacional, el Instituto Goethe de Santiago y el Ministerio de la Cultura y Ciencias del Land Nordrhein-Westfalen de Alemania. A este Festival se ha convocado a toda la ciudadanía del país, mediante comunicados de prensa, radio y redes sociales, con entrada liberada para todas las actividades que se han realizado a contar del pasado lunes 4 de septiembre.

En un artículo publicado el miércoles 6 de septiembre en el diario El Mercurio, quien les habla escribió, en su calidad de Presidente del Instituto de Chile, que la asociatividad interinstitucional que permitió la concreción del Festival se complementa con la interacción disciplinaria en la que está empeñada la directiva, el consejo y las academias que componen el Instituto, la que durante el presente año se ha traducido en un ciclo de conferencias en torno a un tema central: "La innovación tecnológica y sus efectos sobre las diferentes disciplinas". Esto por cuanto en la actualidad se hace necesario pasar de un pensamiento lineal a un pensamiento sistémico transversal, y abordar la sociedad contemporánea en tres dimensiones: la del pensamiento, la de la acción de personas y también de instituciones, y la de vinculación con el conjunto de la ciudadanía.

El Festival Pedro Humberto Allende comprendió las siguientes actividades:

1. Charla magistral de Juan Allende-Blin.

2. Recital de piano del artista alemán Thomas Guenther con obras de Juan Allende-Blin y otros creadores.

3. Charla de Juan Allende-Blin como prolegómeno del Encuentro Nacional que la Asociación Nacional de Compositores organizó en el marco del Festival.

4. Concierto de la Orquesta Sinfónica Nacional bajo la dirección del Maestro Juan Pablo Izquierdo, miembro honorario de la Academia Chilena de Bellas Artes, con obras de Pedro Humberto Allende y Juan Allende-Blin.

5. Concierto de música de cámara con obras de ambos compositores, que se realizará a continuación de esta ceremonia.

Dentro de este marco, el discurso de recepción que me corresponde pronunciar tomará como su principal base de sustento la evidencia a la que toda la ciudadanía del país ha tenido la oportunidad de acceder en las actividades del Festival que han tenido lugar a contar del lunes 4 de septiembre. Esta evidencia pone de relieve los siguientes cinco caminos en los que ha transcurrido el quehacer creativo e intelectual de Juan Allende-Blin.

1. Juan, el creador.

2. Juan, el artista ciudadano.

3. Juan, el pensador.

4. Juan, el investigador.

5. Juan, el maestro. 
Juan, el creador

La conferencia magistral permitió aquilatar importantes antecedentes biográficos de Juan Allende-Blin. En ella el compositor repasa su vida en el Santiago de los años treinta y cuarenta. Evoca sus primeras lecciones de música con su madre, esa inolvidable maestra y persona que fuera la Sra. Rebeca Blin. Señalo estos atributos porque tuve el privilegio de ser su alumno hacia fines de los años cincuenta, en el antiguo Conservatorio Nacional de Música (antecesor del actual Departamento de Música de la Facultad de Artes), ubicado en la calle Bulnes con la Alameda. A este respecto, una precisión respecto del apellido materno del compositor. En Chile, desde siempre lo hemos pronunciado con la "i”. En cambio, para el compositor se debería pronunciar a la manera francesa, en consecuencia con su origen europeo.

En su charla magistral el creador evoca además su relación con su tío Pedro Humberto Allende Sarón, con quien inició sus estudios de composición a los quince años de edad. En su casa escuchó a ese memorable artista del piano que fuera el catalán Ricardo Viñes, interpretar obras de Claude Debussy o tonadas de su tío. Fue en ese hogar donde inició su descubrimiento del entonces nuevo mundo sonoro de Arnold Schoenberg, además de la obra de dos grandes maestros de la polifonía del Cinquecento, Tomás Luis de Victoria y Giovanni Pierluigi da Palestrina. Además, fue allí donde tomó por primera vez contacto con la música de Bach, Beethoven, Mendelssohn, Schumann, Chopin, Grieg, Ravel y César Franck.

Esta incidencia fundamental que tuvo su familia en su formación como músico se entronca con un muy importante rasgo de la historia de la música en el Chile independiente. Señeros son otros casos, como el de Federico Guzmán Frías en el siglo XIX, el primer pianista y compositor chileno de proyección internacional, o en el siglo XX, el de Claudio Arrau, y el de Alfonso, Carmen Luisa y Miguel Letelier, por señalar solamente algunos.

Motivado por estos descubrimientos y por conocer mejor el origen francés de su familia, el compositor parte a Francia y a la entonces Alemania Federal, en los inicios de los cincuenta. En Detmold estudió composición con Günter Bialas y dirección de coros con Kurt Thomas, ulteriormente Thomaskantor en Leipzig. Entre sus condiscípulos en Detmold está Gerd Zacher, destacado organista y compositor alemán, su compañero de toda una vida. Visita en 1952 los Cursos de Música Nueva en Darmstadt, donde conoce a Olivier Messiaen, y a la entonces joven generación de Luigi Nono, Pierre Boulez, y Karlheinz Stockhausen.

Regresa a Chile y como profesor de la cátedra de Análisis Musical del entonces Conservatorio Nacional de Música deja una impronta indeleble en importantes figuras de nuestro quehacer musical, entre estos figura Juan Pablo Izquierdo, Premio Nacional de Artes Musicales 2014, y miembro honorario de la Academia Chilena de Bellas Artes. Posteriormente se radica definitivamente en Alemania, desde donde se erige como una de las grandes figuras de referencia de la música contemporánea.

La obra creativa de Juan Allende-Blin es monumental, y se vertebra, de acuerdo con el catálogo publicado en Essen, con ocasión de su octogésimo cumpleaños, en música para voz o voces solistas, coro, música escénica, instrumentos solistas, conjuntos, música para radio y lo que se denomina como Klangskulptur o esculturas sonoras. En su charla magistral, el compositor identificó como una inquietud de toda su vida, la transgresión de fronteras de todo orden, esto es, ir más allá de los límites entre la música y el lenguaje, entre la música y el espacio, entre la música y el tiempo, entre la música y la interpretación, entre la música y el azar, entre la música y la sociedad, o entre la música y la responsabilidad.

Un concepto muy necesario para la comprensión de su obra es el de tradición. Este término se vincula con "trado" o "tradere", en su acepción de transmisión o entrega. Siguiendo a Igor Stravinsky, se puede explicar como una fuerza viva que desde el pasado ilumina el presente. En el caso de Juan, la tradición familiar es un punto de referencia, o de partida, de su ulterior trayectoria creativa.

Uno de los elementos importantes de esta tradición familiar surge de los aprendizajes recibidos de su tío Pedro Humberto Allende. Entre ellos, el compositor subrayó en su charla magistral, lo que César Franck denominara forme cyclique, vinculada con el procedimiento transformativo de las monumentales arquitecturas polifónicas de maestros franco-flamencos como Johannes Ockeghem y Josquin des Pres. Con una gran musicalidad Pedro Humberto Allende sustenta en este procedimiento su Concierto sinfónico para violonchelo y orquesta (1915), interpretado el pasado 8 y 9 de septiembre por Sebastián Escobar junto con la Orquesta Sinfónica Nacional, bajo la dirección del maestro Juan Pablo Izquierdo.

Ya en 1915 el compositor Alfonso Leng Haygus advirtió este procedimiento, en el detallado análisis que circuló junto con el programa de estreno y que lleva como fecha julio de 1915. Leng 
señala que la forme cyclique se revela en que el "tema principal con que se inicia la obra se presenta, invariablemente, al principio y al fin de cada tiempo [movimientos], además de las reexposiciones". Por su parte, Juan Allende-Blin advierte en el concierto un rasgo visionario, que tuvo un pronunciado impacto en su obra creativa:

"Con esta obra Pedro Humberto Allende dio un paso más allá del de César Franck. Partiendo de una idea generadora de doce sonidos, que no representan el total cromático (ocho que son diferentes y cuatro que se repiten), compuso el concierto con sus tres movimientos en que cada uno tiene un carácter bien determinado (...). Esta manera consecuente de servirse de la forma cíclica fue para mí una especie de puente espiritual que me señaló la ruta hacia la técnica serial de Arnold Schoenberg".

La ruta a la que hace referencia el compositor lo conduce a la transformación desde los sonidos al conjunto de elementos que configuran el total sonoro. Su inicio se pudo apreciar en la Sonatina para piano compuesta entre 1949 y 1950, que ilustró la charla magistral. Además, en el Festival se pudieron apreciar las dos primeras obras de Juan Allende-Blin que llevan el título de Transformations. Estas son, la $\mathrm{N}^{\circ} 1$ compuesta en 1951 para piano solista, vientos y percusión, que interpretó el pianista alemán Thomas Guenther el viernes 8 y el sábado 9 de septiembre, con miembros de la Orquesta Sinfónica Nacional bajo la dirección de Juan Pablo Izquierdo, y la cuarta para piano solista escrita diez años después, que el mismo artista interpretó el martes 5 de septiembre en la Biblioteca Nacional. De acuerdo con la charla magistral, la idea que dio origen a este género surgió hacia fines de los cincuenta en Santiago:

"En 1949 o 1950, aquí en Santiago, analizando las Variaciones op. 27 para piano de Anton Webern observé que eran más radicales que las Variaciones de Arnold Schoenberg, pues no poseían un tema, sino que los tres movimientos que componen esta obra desarrollan una continua transformación. Webern creaba con esta obra un nuevo género que yo denominé Transformations".

En Transformations I, agrega el compositor, "ningún motivo se repite, a partir de ciertas combinaciones de intervalos el discurso se desarrolla renovándose continuamente. Pero el discurso se articula por medio de cadencias. En ellas cambia el tiempo, o sea se realiza una aceleración o un retardo del movimiento. Así hay cadencias, por ejemplo, del clarinete o de la percusión".

Bajo diferentes títulos esta idea de la transformación continua como base o Urlinie se proyecta a importantes obras de Juan Allende-Blin, como Zeitspanne de 1974, interpretada por Thomas Guenther el martes 5 de diciembre, en la que el fluir sonoro interactúa entre el silencio y el sonido reverberado.

La transgresión de fronteras que informa la música de Juan Allende-Blin se pudo apreciar en otras de las obras que sirvieron de ilustración para su charla magistral. La delimitación entre el total cromático como configuración puramente sonora y la linealidad cronométrica del tiempo se puso en evidencia en Sons brisés, tercera parte de Échelons para órgano (1962-1967), escrito a la memoria de Lothar Schreyer e interpretado por Gerd Zacher. La delimitación entre el ballet como trama argumental, y la danza como movimiento corporal que fluye de la sonoridad pura, desde el límite imperceptible hasta el clímax por incremento de la densidad sonora en un amplio rango de timbres, se pudo escuchar en Distances, música para el ballet Séquence de Jean Cebron, presentada en el Grillo-Theater de Essen en 1962. La delimitación entre la sonoridad coral y la visualidad de los textos proyectados se configura como un verdadero contrapunto de lo visual y lo musical en Souffle, para pequeño coro, gran coro y proyecciones visuales (1970-1972), entonado por el Coro de la radio de Colonia bajo la dirección de Manfred Schreier. La delimitación entre el poema como texto, el poema como fonema, el sonido no en una métrica convencional y el tiempo no concordante con un sentido cronométrico resonaron en Fragment nach Hölderlin para soprano, trompeta y eufonio (1984).

El concepto de "collage sonoro" en que se delimita la música y las artes visuales en una perspectiva tanto de exactitud como de aleatoriedad se apreciaron en Palimpsest de 1993. Se combinan tres textos en tres lenguas diferentes, de san Juan de la Cruz, del poeta alemán Alfred Lichtenstein, y de Robert Desnos, todos hermanados por la idea de la muerte.

En una conversación ulterior con el compositor le planteé una idea que el músicólogo alemán Heinrich Besseler utiliza para el motete politextual medieval, en la que por una parte el tenor se basa en un canto gregoriano, la voz intermedia puede entonar un texto secular en francés, y la voz superior un texto religioso en latín. En este caso existe una similitud con la obra de Juan en cuanto a una multitextualidad idiomática. No obstante, los textos no se hermanan por una idea en común como en Palimpsest, por lo que surge la pregunta: ¿Dónde se articula un sentido? La respuesta la entrega un teórico de la época, Johannes de Grocheo, quien señala que este tipo de motetes no se interpretaban en la iglesia, sino que en la sociedad civil. Se puede deducir del planteamiento de Grocheo que la armonía de estas diferencias se daba en la puesta en música (Aufführungpraxis) del motete, en 
una sociedad todavía entrecruzada por lo religioso y lo secular, muy diferente por cierto de nuestra sociedad actual, en la que ambos planos están nítidamente diferenciados. En todo caso, el tema de las armonías de las diferencias es una interesante veta de exploración futura en la indagación de la trayectoria creativa de Juan Allende-Blin.

Lo que se ha señalado se refiere a una pequeña parte de la obra de Juan Allende-Blin. Queda para el futuro la realización de una visión global de su obra creativa. De su fructífera estada en nuestro país, ha sido muy gratificante constatar que a sus 89 años tiene muchos proyectos futuros, los que, estoy cierto, serán aportes relevantes para la música de nuestro país como del resto del mundo.

\section{Juan, artista ciudadano}

El concepto de artista ciudadano fue acuñado por el gran artista visual José Balmes, Premio Nacional de Arte 1999 quien fuera miembro de la Academia Chilena de Bellas Artes. Se refiere a una persona que ejerce su labor artística de manera integrada a su participación en plenitud, dentro del medio social y el período histórico en que le corresponde actuar. En su charla magistral el compositor señaló que su posición ante la sociedad, al igual que su formación como músico, surge de una tradición de referencia familiar:

"Pedro Humberto Allende tenía una posición política bien definida, él era un hombre de izquierda, de una izquierda abierta, sin dogmas, pensamientos heredados de su padre, Juan Rafael Allende, o sea de mi abuelo. De allí se desprendía también la ley moral de mi tío: ser responsable de cada nota que uno compone. Fue para mí su lección esencial".

A lo que él agregó en la misma charla: "Cuando me refiero a la responsabilidad incluyo allí lógicamente mi posición política que debe provenir de una posición moral: ser responsable no solo de cada nota”.

Mucho se podría señalar acerca de esta faceta de Juan Allende-Blin. Se podría hablar acerca del libro titulado Juan Allende-Blin: una vida de recuerdo y utopía, el que fuera presentado en 2002 por prestigiados intelectuales alemanes, y del que la Revista Musical Chilena hiciera una reseña gracias a la colaboración de Hanns Stein, miembro honorario de la Academia Chilena de Bellas Artes. Está por aparecer otro libro en Alemania bajo el título Immer auch ein politischer Impuls (Siempre un impulso político). Se podría hablar además de su inclaudicable condena del nazismo, y de las prácticas políticas de gobiernos como el que se estableció en Chile a contar del 11 de septiembre de 1973.

Pero está además el exilio, que se ha transformado en uno de los temas más candentes en la actualidad a nivel mundial, en particular por la agudización del proceso migratorio debido a múltiples causas sociales, políticas y económicas. Acerca del exilio, Juan se ha pronunciado siempre y de manera clara. A modo de ejemplo se podría señalar su obra Rapport sonore / Relato sonoro / Klangbericht, el que estuvo a cargo de la composición y realización, fue producida entre 1982 y 1983 en Metz, en el Centro Europeo de la Investigación Musical, y finalmente transmitida por la WDR el 23 de marzo de 1983. El mismo año se hizo acreedora al premio Karl-Sczuka de Arte Radial. Al repecto, junto con consignar la noticia de esta distinción, la Revista Musical Chilena publicó la traducción que Hanns Stein hiciera, entre otros antecedentes, de la fundamentación del jurado que discernió el premio: "Son claramente audibles el pasado de una vida vivida y un aislamiento provocado por el exilio. De manera sorpresiva y penetrante la biografía se transforma en historia y en un análisis angustioso de nuestra época".

\section{Juan, el pensador}

Desde una perspectiva global, la charla magistral de Juan Allende-Blin impartida el pasado lunes 4 de septiembre reveló a la ciudadanía nacional un pensamiento acabado acerca de la música. Por otra parte, una mirada muy general acerca de las publicaciones que figuran en el catálogo de su obra revelan una amplia variedad de temas fruto de su refinada cultura.

A modo de ejemplo se podrían mencionar traducciones desde el castellano al alemán realizadas junto con Gerd Zacher de escritos de dos grandes poetas nacionales: Pablo de Rokha (1961) y Vicente Huidobro (1963). El exilio es un tema que figura de manera muy destacada en escritos publicados en 1985, 1989 y 1997. También relevante es el tema del futurismo enfocado de manera genérica (1980,1996), o acotado a Aleksandr Skrjabin (1983), Rusia entre 1910 y 1930 (1993, 2003), o en Italia entre 1909 y 1918 (2001). Su versatilidad le permite abarcar la música de una de las más importantes 
figuras de la primera mitad del siglo XVI, Josquin des Pres con su célebre Missa Pange lingua (1982), al igual que figuras de referencia del siglo XX, como Mauricio Kagel (1991) y Olivier Messiaen (1992). Ha publicado trabajos relevantes en la Revista Musical Chilena acerca de temas como la música contemporánea a fines de los 70 (1970), Fré Focke y la tradición de Anton Webern (1997), la obra de su tío Pedro Humberto Allende Sarón (2002), los caminos de los exiliados (2003), y Fernando García, Premio Nacional de Artes Musicales 2002, miembro de número de la Academia Chilena de Bellas Artes (2003).

Juan, el investigador

Estrechamente vinculado con el camino anterior está la labor de Juan como investigador. Su trabajo se traduce en escritos rigurosamente formulados, de acuerdo con los más exigentes cánones de la musicología. Pero su trabajo como investigador no se agota en el documento científico, toda vez que está de manera íntima relacionado con su actividad como compositor.

En dos ocasiones del Festival Pedro Humberto Allende, la ciudadanía tuvo la oportunidad de apreciar los resultados musicales del incansable trabajo de Juan como investigador. En el recital de piano, ofrecido por Thomas Guenther en la Sala América el martes 5 de septiembre, obras suyas como Transformations IV (1961) y Zeitspanne (1974) entraron en diálogo con obras de creadores del así denominado futurismo ruso, como Nikolaj Obouchov, Ivan Wyschnegradsky, Nikolai Roslavetz y Alexander Mosolov. Además de los escritos pertinentes a este tema señalados en el epígrafe anterior, Juan indicó en las palabras introductorias al concierto, que personalmente se había sumergido en los archivos rusos en Moscú para pesquisar partituras que resultaran musicalmente representativas de este movimiento. En una conversación posterior, el mismo Juan planteó dos grandes raíces de la vanguardia de la primera parte del siglo XX. Una es la centroeuropea que se remonta a la raíz católica del Viejo Mundo. La otra es la rusa, que se remonta a la raíz bizantina tanto de Rusia misma como los países de Europa Oriental que fueron cristianizados y alfabetizados por la iglesia bizantina. Se trata de un tema fascinante que indudablemente permitirá replantear la historia de la música del siglo XX, la que hasta la fecha se ha concentrado prioritariamente en la vertiente centroeuropea.

La segunda ocasión fue la presentación musical de La Chute de la Maison Usher, fragmento de una ópera de Claude Debussy acerca de un texto de Edgar Allan Poe reconstruido por Juan. El minucioso proceso de detección de los fragmentos que encontrara en la Biblioteca Nacional de París, se complementó con un proceso de investigación, en las palabras del creador, "en muchas ciudades y en muchos países; como en una novela policial seguí la borrosa pista”, junto con lo que pudo recabar de la hija adoptiva de Debussy, Madame Dolly de Tinan, lo que le "sirvió no solo para completar el fragmento sino también para determinar más estrechamente la fecha de esta música”. Los resultados del proceso de investigación se publicaron en Munich, Alemania (1977), París, Francia (1978), y Stuttgart, Alemania (1980). El texto francés publicado en la revista Musique en Jeu (1978) fue traducido por Miguel Aguilar y publicado en la Revista Musical Chilena ${ }^{10}$. El ciudadano interesado podrá cotejar este último texto con la magnífica versión de la música que se realizara el viernes 8 y el sábado 9 de septiembre por la Orquesta Sinfónica Nacional, bajo la dirección de Juan Pablo Izquierdo con la participación de destacados solistas nacionales.

Juan, el maestro

Personalmente no conocía a cabalidad esta faceta de Juan. La pude apreciar en la conversación abierta efectuada el miércoles 6 de septiembre en la Sala Ercilla de la Biblioteca Nacional. En esa ocasión Juan planteó que su enfoque de la enseñanza de la composición toma como su punto de partida el tratamiento de la melodía. Personalmente lo encontré muy novedoso y fue de suma utilidad en la ulterior mesa de conversación acerca de La enseñanza de la composición en Chile, organizada en el marco del Festival Pedro Humberto Allende por la Asociación Nacional de Compositores. Muy relevante fue la participación en esa mesa moderada por Gabriel Matthey, de los creadores Antonio Carvallo (Presidente de la Asociación Nacional de Compositores), Pablo Aranda, Eduardo Cáceres, Alejandro

10 Juan Allende-Blin, "En busca del Debussy perdido", Revista Musical Chilena, XLIX/184 (1995), pp. 11-37. 
Guarello y Aliocha Solovera. Todos ellos enseñan composición en Chile en la actualidad, por lo que el interesante intercambio de puntos de vista permitió aquilatar que la tradición de referencia de Pedro Humberto Allende como maestro de composición sigue plenamente vigente en nuestro país.

\section{EPÍLOGO}

La conjunción de los cinco caminos señalados de Juan Allende-Blin, como compositor, como artista ciudadano, como pensador, como investigador y como maestro, abordadas someramente en este discurso, demuestra que su incorporación a la Academia Chilena de Bellas Artes del Instituto de Chile como miembro honorario, junto con constituir un señalado honor para la institución, le ofrece a Juan Allende-Blin un marco institucional desde el que podrá continuar su aporte a la cultura de nuestro país, por lo que le deseamos muchos y fructíferos años de vida.

Muchas gracias por su atención.

\section{JUAN ALLENDE-BLIN, DISCURSO DE INCORPORACIÓN A LA ACADEMIA CHILENA DE BELLAS ARTES \\ Martes 12 de septiembre de 2017, 19:00 horas, Instituto de Chile, Salón de Honor}

Es para mi persona un honor y un placer el haber sido elegido como miembro honorario de la Academia Chilena de Bellas Artes. Les agradezco además la ocasión que me proponen de dar a conocer ciertos aspectos de mi trabajo. En mi conferencia del pasado 4 de septiembre expuse un bosquejo de la evolución de mi lenguaje musical. Creo ser el inventor de lo que he denominado collage sonore, en referencia a esas obras realizadas en un estudio, en que fijo -como un pintor su cuadro, o un escultor sus figuras- en forma definitiva por medio de construcciones precisas, pero a la vez haciendo intervenir el azar en la integración de los componentes del conjunto. Esa mezcla entre composición estricta y el azar es mi sello personal. Otro aspecto de mi labor es el estudio de las relaciones entre los lenguajes. Me refiero al lenguaje exclusivamente sonoro (la música) y el lenguaje verbal (la poesía, la prosa). Ambos lenguajes producen pensamientos que solo pueden expresarse o mediante la combinación de sonidos o mediante las palabras que componen el poema, la novela, el cuento.

En la búsqueda de esas interrelaciones estudié los métodos del pensamiento de la cábala hebrea, en relación con el lenguaje musical de Arnold Schönberg. El extenso estudio que le dediqué se publicó en la revista Musik-Konzepte, en un número doble dedicado a Schoenberg ${ }^{11}$. Al hacer este estudio tuve que recurrir a viejos tratados; a modo de ejemplo los de Giovanni Pico della Mirandola (Mirandola, 1463-Florencia, 1494), o de Athanasius Kircher (Geisa, Alemania 1602-Roma, 1680), como también de los textos de Sigmund Freud o de Franz Kafka, sobre todos los Diarios de este último. Todos ellos convergen en que la mente humana en su gran complejidad produce relaciones nocturnas, o sea, inconscientes.

La lengua hebrea posee una cualidad, que es, a la vez, calidad: sus letras representan tanto números como fonemas. Así, cada palabra representa, además de su significado semántico, un número preciso. Por otra parte, cada sonido se identifica por el número de frecuencias. Su relación horizontal o vertical con otros sonidos también se identifica por números, como ser segunda, cuarta, quinta. Pero, a la vez, los sonidos tienen un contenido emotivo. A modo de ejemplo, los salmos son simultáneamente textos y colecciones de números, los que, por otra parte, responden a otros significados semánticos. Kafka estudió este saber cabalístico con su amigo František Langer (Praga, 1888-Praga, 1965). El saber de estos estudios se repartía difusamente en el pueblo hebreo, en los shtetl, o sea, aquellas pequeñas aldeas en los países de la Europa Oriental, que eran centros concentrados de sabiduría cabalística, y que fueron destruidas definitivamente por los alemanes nazis y sus secuaces de otros países.

11 Juan Allende-Blin, "Arnold Schönberg und die Kabbala-Versuch einer Annäherung“, en: Arnold Schönberg. Musik-Konzepte Sonderband, ed. Heinz-Klaus Metzger y Rainer Reihn, Munich: text + kritik 1980, pp. 117-145. 
Entre los siglos XV y XVII, personajes como Pico della Mirandola o Athanasius Kircher eran cristianos ricos y poderosos, que hicieron traducir al latín algunos textos cabalísticos hebreos. Ellos mismos escribieron tratados cabalísticos, cristianizándolos. Estos pensamientos los conoció J. S. Bach, quien los aplicó en su método de composición. En Bach, ciertos números poseen un valor especial. Así, por ejemplo, el número 43 indica un centro de la composición, cuyo valor es esencial para las proporciones de la obra. Mi amigo y compañero de vida Gerd Zacher hizo análisis increíbles acerca de las proporciones que articulan el discurso musical de Bach.

Y bien, Arnold Schönberg conocía también la obra de Bach, pero sin saber con precisión lo que hoy es parte del conocimiento. No obstante, Schönberg intuyó estas proporciones. El pensamiento acerca de lo que este compositor denominó como "Sistema de las relaciones entre los doce sonidos" nació inconscientemente del pensamiento cabalístico. Schönberg conocía el procedimiento de los compositores que trabajaban con un cantus firmus, y su capacidad propia de producir la unidad, al aplicar las relaciones entre los intervalos del cantus firmus, aun cuando, o precisamente, estos sonidos se utilizaran con ritmos diferentes. Para ello se debe distinguir entre el aspecto consciente y el aspecto inconsciente. En el primero de ellos se sumerge este conocimiento en el ser humano. Por su parte, el inconsciente trabaja con este material para crear, a modo de ejemplo, el sistema de los doce sonidos de Schönberg. Esta manera de pensar de Schönberg se vincula con el lenguaje hebreo, en el que la relación entre número y significado es propicia para elaborar un sistema de una complejidad especial, en el que se distingue a lo menos dos capas, una es la percepción sonora directa; la otra consiste en penetrar en el orden y las proporciones de los sonidos.

$\mathrm{Al}$ analizar estas relaciones entre el pensamiento cabalístico y la música de Arnold Schönberg, me vi obligado a estudiar en la historia de la música una relación subcutánea con la música cristiana. El comienzo es el canto gregoriano, una de cuyas raíces es la cantilena judía. La música gregoriana influyó directamente; también lo hizo en la música polifónica hasta aproximadamente el año 1600. En esta última época se interesaron varios eruditos cristianos por la cábala hebrea. En el siglo XIII vivió Abraham Abulafia (Zaragoza, 1240-Comino, Malta 1291), autor del Libro de la permutación (Sefer Ha-Tzeruf), en el que sistematiza las permutaciones con el alfabeto hebreo, el que en su modalidad escrita emplea solamente consonantes. Esto significa que las permutaciones de un determinado texto permiten un juego de combinaciones con nuevos significados semánticos. De esta manera, diferentes lecturas del Antiguo Testamento podrían producir diferentes significados de un determinado texto. Así, una primera lectura correspondería al significado literal del texto. Una segunda lectura podría referirse al valor numérico de las palabras de ese texto. Las lecturas ulteriores son posibles mediante las permutaciones que propone Abraham Abulafia.

Esta modalidad del pensamiento hebreo se extendió por la Europa medieval. El mismo Abulafia trabajó en España y en Italia, para fallecer en Malta. Esto caracteriza además la biografía de otros cabalistas nacidos en la región mediterránea, quienes, sin mediar fronteras, se dirigían de una comunidad hebrea a la otra. Esta manera de pensar se difundió ulteriormente al norte de Europa, si bien en este proceso el pensamiento de Abulafia se fue diluyendo. No obstante, el fondo matemático de su pensamiento permaneció. A modo de ejemplo se pueden señalar las novelas y los cuentos de Kafka además de los textos analíticos de Freud. Estas obras de Kafka no concluyen de manera definitiva, y permanecen como fragmentos. Se pueden interpretar de diversas maneras como parábolas, que nos permiten vislumbrar el pensamiento subcutáneo de Abulafia. Por su parte, Freud, contemporáneo de Kafka, estudió profundamente el inconsciente y los sueños, los que son objeto de diversas interpretaciones, en términos de los símbolos.

Arnold Schönberg, a la vez contemporáneo de Kafka y de Freud, interpenetra de manera inconsciente y subcutánea en sus conocimientos musicales el pensamiento diluido de Abulafia, y lo concretiza en el sistema de los doce sonidos dentro de un proceso evolutivo. En 1908 compone el Cuarteto $\mathrm{N}^{\circ}$ 2, op. 10, en fa sostenido menor. En el tercer movimiento de esta obra, "Litanei", le agrega la voz de soprano sobre este poema de Stefan George, en el que transgrede las fronteras de la tonalidad. Esa transgresión se profundiza en las obras siguientes compuestas entre 1908 y 1923. En esa situación, al emplear el total cromático, Schönberg busca una manera de controlar esta transgresión de la tonalidad.

Entre el Cuarteto $\mathrm{N}^{\circ} 2$ y la Suite op. 25 compone Schönberg varias obras en un estilo que se ha denominado atonalidad libre. Pero al detallar un análisis de estas obras se decanta que él busca relaciones precisas entre intervalos, mediante procedimientos contrapuntísticos como el canon y la passacaglia, los que se destacan especialmente en el Pierrot lunaire op. 21. Este proceso culmina con el empleo sistemático de los doce sonidos en la Suite op. 25 para piano. Schönberg mismo quería ver en este proceso 
solo una ampliación del sistema tonal. Pero el empleo consecuente de los doce tonos crea un nuevo mundo sonoro, sustentado en el uso de las relaciones interválicas entre los sonidos. Además, el sistema de doce sonidos se sustenta en el microcosmos de los sonidos que se están formando, mientras que el sistema tonal se basa en relaciones de acordes perfectos en un sistema guiado por las quintas justas. En el sistema tonal, la quinta superior a la tónica se denominó dominante, mientras que la quinta inferior se conoció como subdominante. La tercera superior en general es mayor, mientras que la tercera inferior en general es menor. De allí se desarrolló un sistema tonal cada vez más complejo, que medía el discurso por las distancias de quintas, las que, por otra parte, partiendo de los acordes perfectos mayor y menor, los compositores los desarrollaron mediante la agregación de sonidos por terceras.

En un análisis de Gerd Zacher en donde estudia el Contrapunto XI de El Arte de la Fuga, él constata que este contrapunto está articulado por cuatro cadencias, la primera sobre si bemol, que en la terminología alemana corresponde a la letra B; la segunda cadencia es sobre la, o sea A; la tercera cadencia es sobre do, o sea C, mientras que la cuarta cadencia es sobre el si natural, que es $\mathrm{H}$. Esto significa una interdependencia del pensamiento contrapuntístico que emplea las cadencias como medios de puntuación. A la vez son mensajes subcutáneos al intérprete, que en esos signos debe ver las congruencias entre la gran forma y sus partes integrantes. Por su parte, Schönberg y compositores en torno a él empleaban los doce sonidos inventando así nuevos acordes, algunos de ellos por cuartas justas, aumentadas o disminuidas, además por séptimas y novenas mayores y menores, y las combinaciones de ellas. Este mundo así creado es un juego sutil de diversas combinaciones y permutaciones, en las que se traslucen las ideas de Abulafia.

En el año 1933, cuando Hitler asume el poder en Alemania, Arnold Schönberg es destituido de su cátedra de composición en la Academia de las Artes de Berlín. En ese crucial momento, Schönberg solidariza con todas las víctimas judías del nazismo. En París, el compositor reingresa a la religión judía en una ceremonia en la que su exalumno Max Deutsch y Marc Chagall sirven de padrinos. A partir de este momento, Schönberg compone salmos hasta su muerte. La obra más impresionante de esta solidaridad es Un sobreviviente de Varsovia para narrador, coro y orquesta. Al final de esta obra canta el coro la oración "Escucha Israel" (Shema Israel). Así culmina la conjunción entre Abulafia, sus pensamientos acerca de las permutaciones, y el sistema de los doce sonidos.

\section{Apéndice al Discurso de Incorporación a la Academia Chilena de Bellas Artes ${ }^{12}$}

Quisiera extender un poco mi discurso, para así fundamentarlo en un contexto mayor. Para demostrar cómo se origina el lenguaje, resultan interesantes las consideraciones de Giambattista Vico (1668-1744) en su libro Principi di una scienza nuova d'intorno alla commune natura delle nazioni (1725). También es interesante constatar que Jules Michelet (1798-1874) tradujo este libro al francés cien años después:

"el lenguaje fue primero mental, en la época en que el hombre no conocía aún el uso del habla (tempi mutoli...); aquel lenguaje primitivo, que precedió el lenguaje articulado, debió consistir en unos signos, gestos u objetos que tenían unas relaciones naturales con las ideas"13.

Probablemente el lenguaje musical no se haya desarrollado de manera muy diferente. En su Encyclopédie, Denis Diderot (1713-1784) publicó agudas observaciones respecto del siguiente estadio en el desarrollo del lenguaje. En relación con las artes como sistemas de signos, observa: "Es la cosa en sí lo que muestra el pintor; las expresiones del Músico y del Poeta solo son unos jeroglíficos de aquellos"14. Y continúa:

12 Juan Allende-Blin, Essen, Alemania, 7 de noviembre de 2017. Traducido del alemán por Daniela Fugellie.

13 Julia Kristeva, El lenguaje, ese desconocido, traducción de María Antoranz, Madrid: Fundamentos, 1999, p. 176.

14 Ibid., p. 186. 
"Ahí donde tenga lugar el jeroglífico occidental: ya sea en un verso, ya sobre un obelisco; igual que aquí es obra de la imaginación y allá la del misterio; precisará para ser comprendido o bien una imaginación o bien una sagacidad poco comunes... Cualquier arte de imitación que tenga sus jeroglíficos particulares, yo quisiera que alguna mente instruida y delicada se dedicara un día [a] compararlos entre sî" 15 .

El escrito de Julia Kristeva Le langage, cet inconnu (El lenguaje, ese desconocido) construye un puente entre los postulados de Diderot en relación con los jeroglíficos y los de Freud relativos al sueño: "El sueño que estudia Freud está igualmente considerado como un sistema lingüístico por descifrar, ante todo, y más aún, como una escritura con reglas semejantes a las de los jeroglíficos"16.

En su Carta sobre los ciegos, Diderot afirma que solo pocos hombres pueden reducir todo a cifras, en un acto de pura abstracción: "Hay una clase de abstracción de la que son capaces tan pocos hombres que parece reservada a las inteligencias puras, es aquella mediante la cual todo se reduciría a unidades numéricas" 17 .

Y con esta idea retornamos a Abraham Abulafia.

Las permutaciones de las cifras del judío Abulafia trascienden lo puramente lúdico, ya que constituyen también símbolos de letras del alfabeto, las que a su vez pueden producir un lenguaje con sentido semántico. Aquí se interrelacionan el pensamiento árabe y el judío. Las cifras o números árabes nos llevan a los signos del alfabeto hebreo, produciendo misteriosas asociaciones. Los textos de las Sagradas Escrituras se cantan, como cantinela o vocalización. Lo que se escribe son las consonantes, mientras que las vocales se anotan como accents (ad cantus). De esta manera, las palabras se transforman en canto.

Todos estos elementos generan lenguajes -de los sonidos, de las palabras, de las imágenes, es decir: música, poesía, pintura-. Todos ellos requieren una sintaxis, lo que significa coherencia y relaciones mutuas que van produciendo diversos significados. Las sintaxis evolucionan constantemente, ya que sus componentes conservan su vitalidad. Así el vocabulario, o sea el lenguaje de signos, se va renovando y creando nuevas relaciones semánticas. También las permutaciones de Abulafia, que incitan a producir estados místicos, pueden crear nuevas formas de comprensión y de comunicación.

Nuestra gestualidad, nuestros jeroglíficos se refinan día a día y nunca dejan de permutar, permitiéndonos decir lo indecible. Pese a su precisión, la escritura de nuestros lenguajes, de todos los lenguajes, continúa siendo jeroglífico y palimpsesto, ya que preserva ocultas las tradiciones de tiempos pasados. Detrás y entre los signos de nuestra música de tradición escrita se esconden las permutaciones de Abulafia, pero también las construcciones de Guillaume de Machaut y probablemente también las sabidurías del viejo Bach. Basta con leer en lo profundo.

La invención de los lenguajes se basa en un juego de permutaciones. Las reglas del juego varían y así surgen obras que, en palabras de Theodor W. Adorno en su Einleitung in die Musiksoziologie (Introducción a la sociología de la música) de 1968, "son unidades que poseen una estructura y un sentido en sí mismas, las que se abren al análisis y pueden ser percibidas y experimentadas con diversos grados de exactitud"18.

Un tiempo después, Adorno reflexionó acerca de una función utópica del tiempo en la música: "Esto quiere decir (...) que en la música, como arte del tiempo, todos sus momentos poseen la facultad de un constante devenir y a la vez refieren más allá de sí mismos" 19 .

El lenguaje musical de Schönberg se fundamenta en esta tradición plural.

\section{Ibid.}

16 Ibid, p. 270.

17 Denis Diderot, Carta sobre los ciegos para uso de los que ven, Buenos Aires: El cuenco de plata 2005 , p. 58.

18 "ein in sich Strukturiertes und Sinnvolles sind, das der Analyse sich öffnet und das in verschiedenen Graden der Richtigkeit wahrgenommen und erfahren werden kann”. Theodor W. Adorno, Einleitung zur Musiksoziologie, en: Gesammelte Schriften, ed. Rolf Tiedemann, vol. 14, Berlín: Suhrkamp 2003, p. 180. Traducción de Daniela Fugellie.

19 "Das heißt (...), daß in der Musik überhaupt, als in einer Zeitkunst, alle Momente etwas Werdendes haben und über sich hinausweisen". Theodor W. Adorno, "Zum Problem der musikalischen Analyse”, Frankfurter Adorno Blätter, ed. Rolf Tiedemann, vol. 7, Munich: edition text \& kritik, 1992, p. 86. 